\title{
Open Reconstruction of Huge Abdominal Aortic Aneurysms: Postoperative Complications
}

\author{
Amr M. Salem1, MD;1 Sameh Moustafa, MD;2 Tarek M. Salem, MD;3 \\ Mohamed E. Salem Ph.D. ${ }^{2}$
}

1) Vascular Surgery, Medical Research Institute, Alexandria University, Egypt.

2) Vascular Surgery, Faculty of Medicine, Alexandria University, Egypt.

3) Internal Medicine, Faculty of Medicine, Alexandria University, Egypt.

Purpose: Was to study the results of open surgical reconstruction of huge abdominal aortic aneurysms (HAAAs) \& their complications.

Patients and methods: Twenty eight patients with huge abdominal aortic aneurysms were studied in the period from October 2012- March 2015. The diagnosis was done by: history, clinical examination, various imaging which included: Duplex Ultrasound, CTA, MRA, DSA \& Mid-stream aortography. Open aortic reconstruction was done by using Bifurcated graft (Collagen coated or PTFE ) or aneurysmorrhaphy in two cases of mycotic saccular aneurysms.

Results: The age incidence ranged from 45-78 years with a mean of 64 years. Male sex was predominant than female sex with M:F ratio 6:1. There was a history of Diabetes mellitus, smoking, hypertension, hypercholesterolaemia, obesity, myocardial infarction (seven cases) \& renal impairment (two cases). The most common presentation of AAAs were abdominal pain, back pain, pulsating abdominal mass \& acute abdomen (in two leaking AAAs). The size of the aneurysm (diameter) ranged between 12-22 cm with a mean of $16 \mathrm{~cm}$, the size was measured by Duplex Ultrasound \& CTA. Postoperative Morbidity: lower limb ischemia due to arterial thrombosis was present in two cases \& distal embolization in two cases, thrombectomy \& embolectomy were done respectively \& successfully except one big toe amputated after embolectomy. Myocardial infarction occurred in four cases, two of them died. Another two cases developed uraemia, one of them died. Leaking abdominal aortic aneurysms occurred in two cases, one of them died. The overall all mortality rate within thirty postoperative days was four cases (14.3\%), no intraoperative mortality.

Conclusion: The morbidity \& mortality rates were proportional with increase in size of the aneurysm \& increase with the presence of preoperative cardiac, renal dysfunction \& risk factors.

Key words: Open reconstruction, abdominal aortic aneurysm (AAA), pulsating abdominal mass, lower limb ischemia \& back pain.

\section{Introduction:}

Abdominal aortic aneurysm (AAA) is a prevalent threat, affecting approximately $5 \%$ of males over the age of 65 . Open aneurysm repair (OAR) has been performed since the 1950s with a 30-day mortality of 4-12\%. ${ }^{1}$

Abdominal aortic aneurysms (AAAs) are the 10th leading cause of death in men over 55 years of age. The incidence of AAAs in
$60-70$ years old patients is $4 \%$ in men and $1 \%$ in women. The incidence increases with age in both sexes. Family history is an important predictor of aneurysm development. ${ }^{2}$

The infrarenal aorta is the most common location for clinically significant aneurysms. Among AAAs undergoing surgical repair, about $95 \%$ are infrarenal, only 5\% involve the suprarenal aorta. ${ }^{3}$ 
Most AAAs (about 75\%) cause no symptoms unless they rupture. AAAs may cause chronic abdominal or back pain, acute ischemia of the lower limbs due to embolization or local dissection (both in 2-5\%) and usually presented by pulsating abdominal mass. Occasionally AAAs cause local compression. ${ }^{4,5}$

Rupture continues to be the eventual fate of AAAs, which results in: Sudden abdominal or back pain, hypotension and shock, and a pulsatile abdominal mass. Mortality rates after rupture are ranged from $15 \%$ to $94 \%$ with an average of 50\%.6,7

An abdominal aortic aneurysm is usually diagnosed by history, physical examination, ultrasound, or CTA, plain radiographs, MRA and DSA. ${ }^{8}$

There are currently two modes of repair available for an AAA: open aneurysm repair (OR), and endovascular aneurysm repair (EVAR). An intervention is often recommended if the aneurysm grows more than $1 \mathrm{~cm}$ per year or it is bigger than $5.5 \mathrm{~cm} .{ }^{9}$ Repair is also indicated for symptomatic aneurysms. ${ }^{10}$

Open repair is indicated in young patients as an elective procedure or in growing or large aneurysm (more than $5.5 \mathrm{~cm}$ ), symptomatic or ruptured aneurysms, also open repair is indicated if EVAR is contraindicated as in short aortic neck less than $15 \mathrm{~mm}$, angulation more than 45 degrees, dilated aortic neck, the shape of the neck is irregular, conical or reverse conical neck, localized posterior bulge in the neck (double bubble), a symmetry of the wall of the neck and eccentric laminated thrombus. There is strong evidence that open repair is durable. ${ }^{11-13}$

EVAR: It is generally indicated in older, high risk patients unfit for open repair. The main advantages of EVAR is less perioperative mortality, less time in intensive care and less time in hospital. ${ }^{14-17}$

Disadvantages of EVAR include a requirement for more frequent ongoing hospital reviews and higher chance for further procedures being required. The EVAR does not offer any benefit for overall survival or health-related quality of life compared to open repair. ${ }^{18-21}$ There are also significantly higher risks of reintervention and aneurysm rupture after EVAR. ${ }^{22}$

The postoperative mortality for an already ruptured AAA has slowly decreased over several decades but remain higher than $40 \% .^{5}$ However, if the AAA is surgically repaired before rupture, the postoperative mortality rate is lower: approximately $1-6 \% .6,23,24$

\section{Aim of the work:}

The aim of this work was to evaluate the results of surgically reconstructed huge abdominal aortic aneurysms (HAAAs) as regard morbidity and mortality.

\section{Patients:}

After local ethical committee of the Faculty of Medicine, Alexandria University approval and obtaining fully informed patients consent, the current study was conducted on twenty eight patients with huge abdominal aortic aneurysms (HAAAs) who admitted to the Alexandria Main University Hospital, Faculty of Medicine, Alexandria University and Moustafa Kamel Millitary Hospital, Alexandria, Egypt , in the period from October 2012- March 2015.

\section{Methods:}

All cases were diagnosed by: history, clinical examination, laboratory investigations, Duplex US, CTA, MRA and DSA. ECG and echocardiogram were done for every case. Aortic reconstruction was done by using artificial bifurcated grafts (collagen coated graft and PTFE graft). Aneurysmoraphy was done in two cases of mycotic saccular type.

\section{Results:}

The age incidence ranged between 45-75 years with an average of 64 years. Male sex was predominant than female sex with a $\mathrm{M}: \mathrm{F}$ ratio 6:1.

All cases were subjected to routine laboratory investigations which were normal or controlled. Diagnosis was done by Duplex US and CTA for all cases, while MRA \& DSA were used in three cases. Plain X-ray 


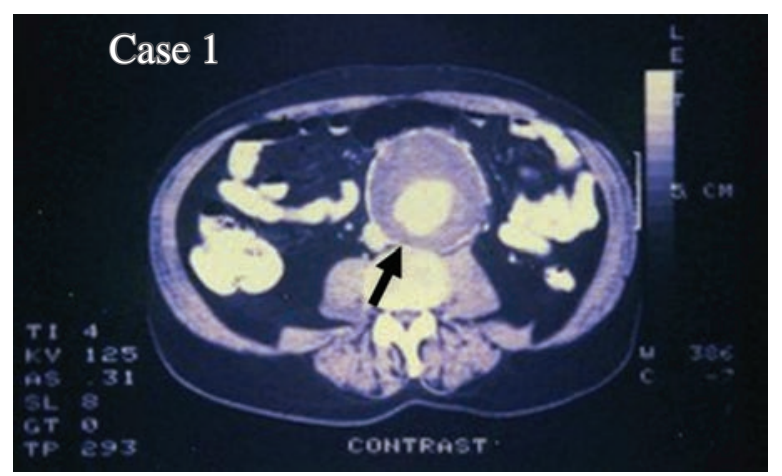

Figure (1): CTA of huge AAA with a diameter $15 \mathrm{~cm}$.

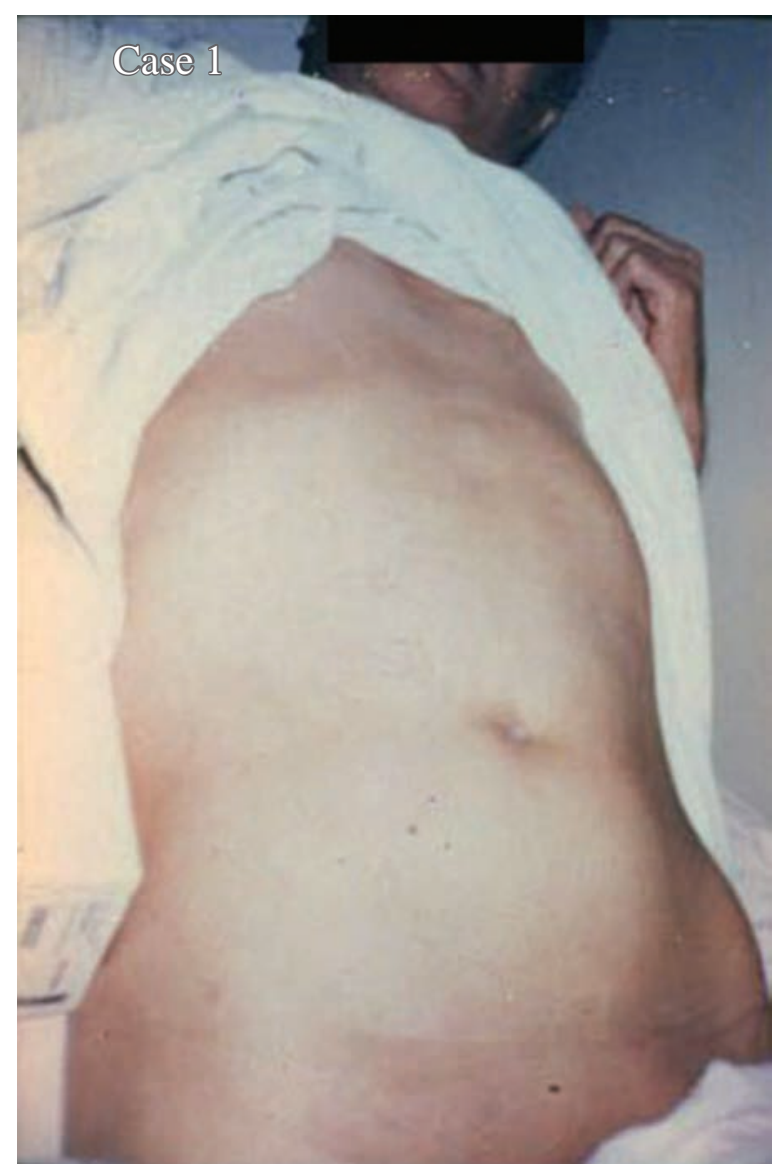

Figure (3): Photo of the abdomen before operation showing abdominal bulge.

was done to visualize calcifications in the aneurysmal wall in five cases.

Open repair was done for all cases. 26 cases reconstructed by using bifurcated grafts: Collagen coated in 14 cases and PTFE in 12 cases. Two cases with saccular aneurysms were treated by lateral repair using artificial patch graft. Three cases were represented in the result before and after

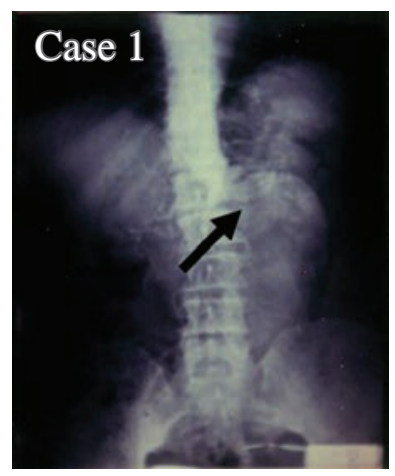

Figure (2): CTA of AAA with angulated \& dilated asymetrical neck.

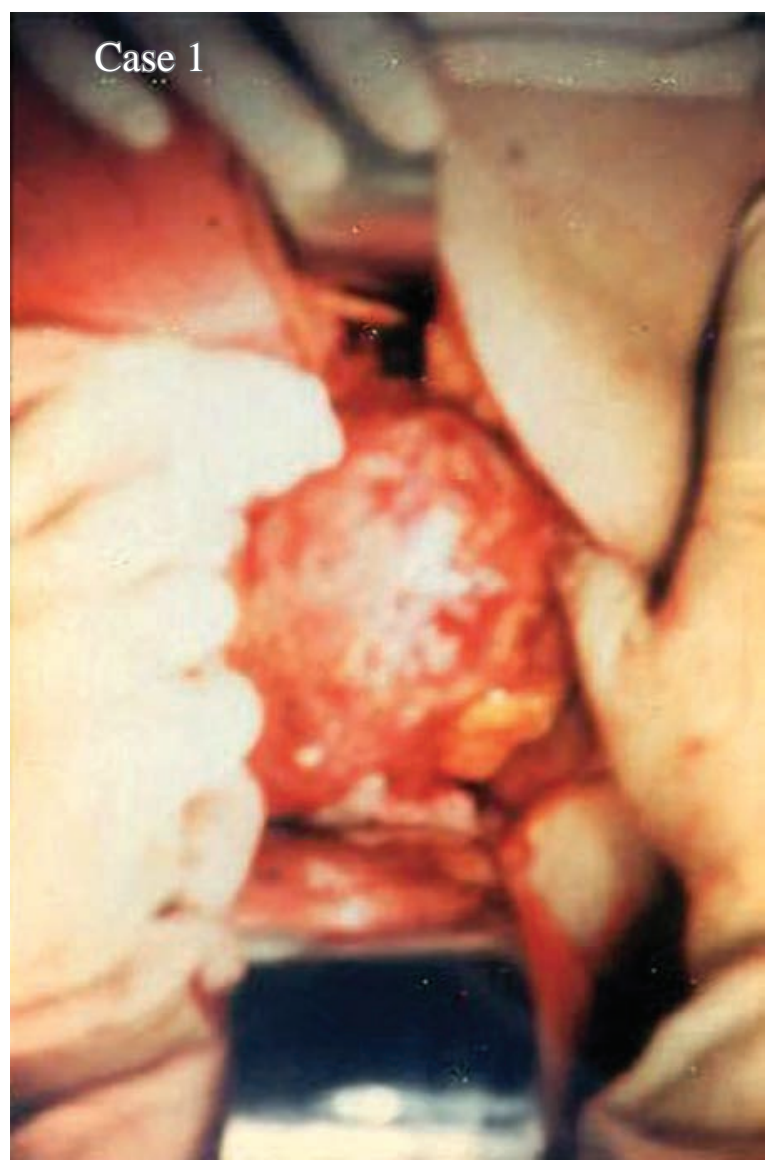

Figure (4): Photo of the huge size of the aneurysm $15 \mathrm{~cm}$ during operation after opening of the abdomen.

30 days of aortic reconstruction: Case (1): Figures (1-8). Case (2): Figures (9-14). Case (3): Figures $(15,16)$.

The size and the diameter of AAAs were measured by Ultrasound and CT scan. The largest diameter of the aneurysms ranged between 12-22 cm. with an average of $16 \mathrm{~cm}$. we consider any AAA with diameter ten $\mathrm{cm}$ or more is a huge AAA 


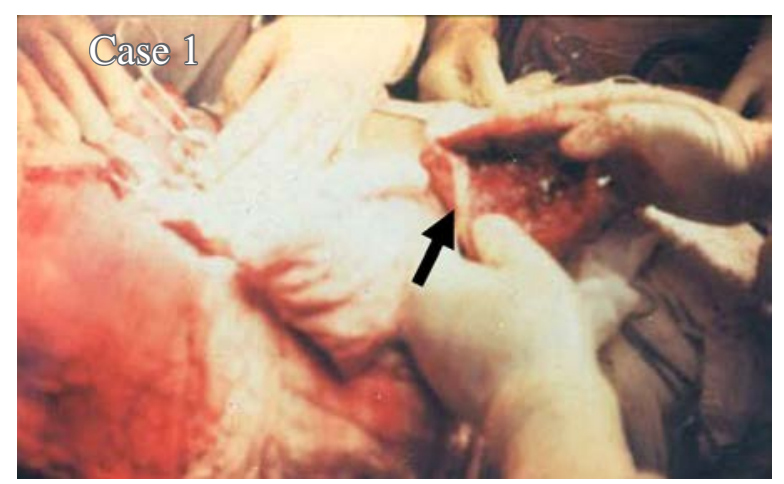

Figure (5): Photo of the laminated thrombus outside the aneurysm.

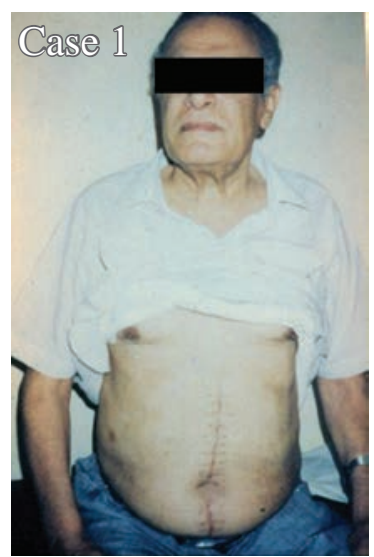

Figure (7): Photo of the abdominal wound after 30 days of the operation.

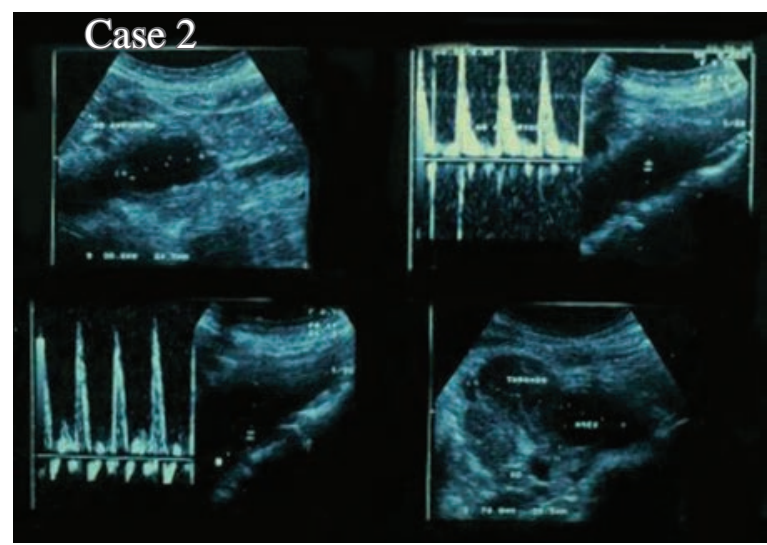

Figure (9): Duplex US showing AAA.

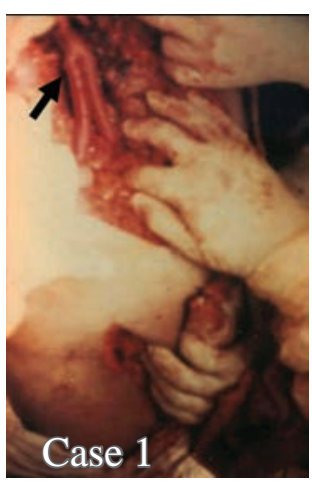

Figure (6): Photo of the bifurcated graft after aortic reconstruction.

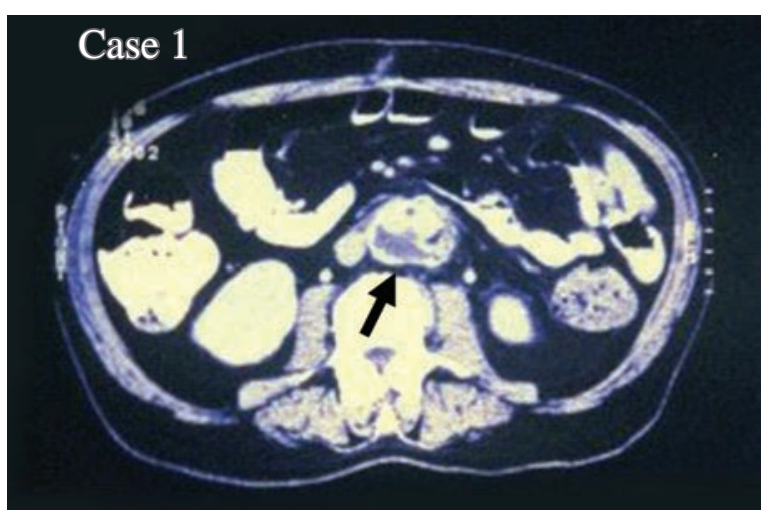

Figure (8): Postoperative CTA showed the two limbs of the bifurcated graft, 30 days after operation.

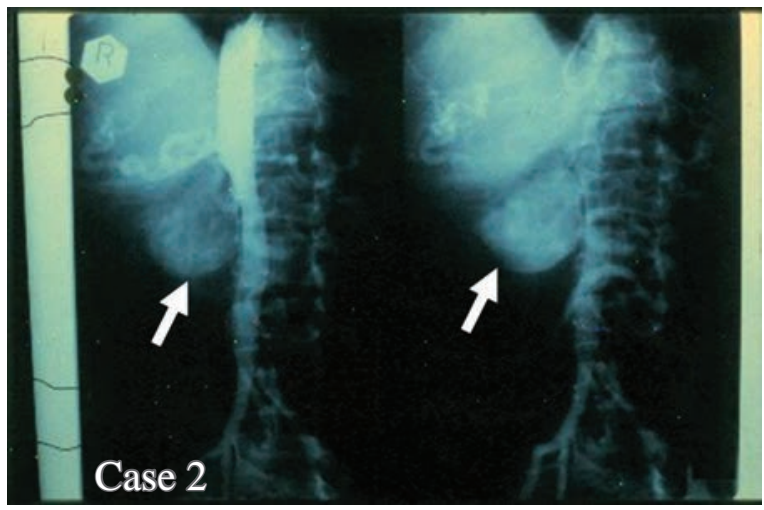

Figure (10): CTA showed aneurysm $18 \mathrm{~cm}$ in diameter compressing the abdominal aorta to the left side and simulating Rt. renal artery aneurysm.

aneurysms. Also, if EVAR is contraindicated. There is strong evidence that open repair is durable. ${ }^{12}$ Endovascular repair is associated with more reinterventions and requires periodic imaging for the remainder of the patient's life. The clearest indication for endovascular repair had been assumed to be patients who are athigher risk from open repair. 


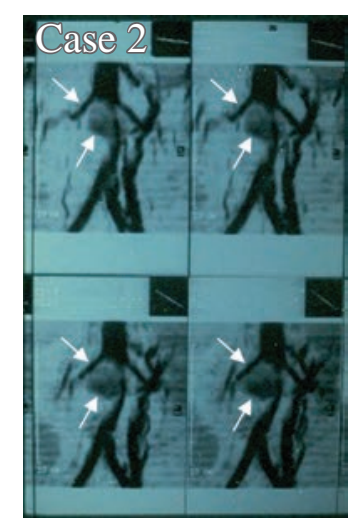

Figure (11): MRA showed normal Rt renal artery. It was saccular AAA arising from the frant of the aorta (juxta renal).

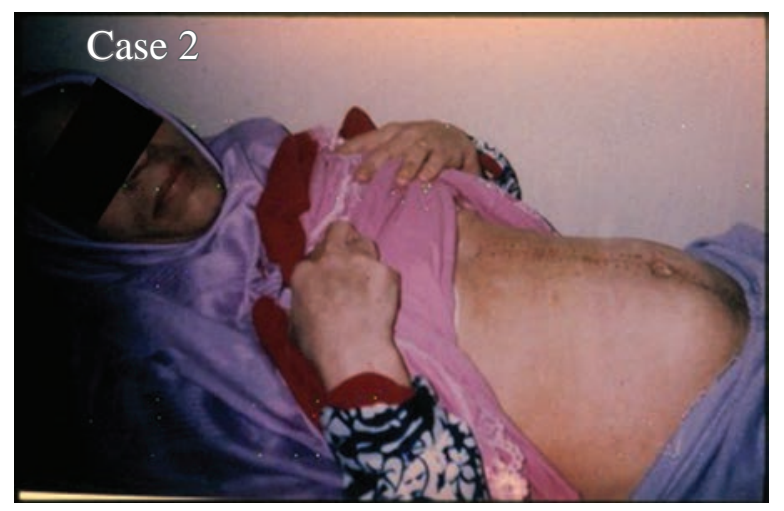

Figure (13): Postoperative photo of the abdomen after 30 days (healed wound).

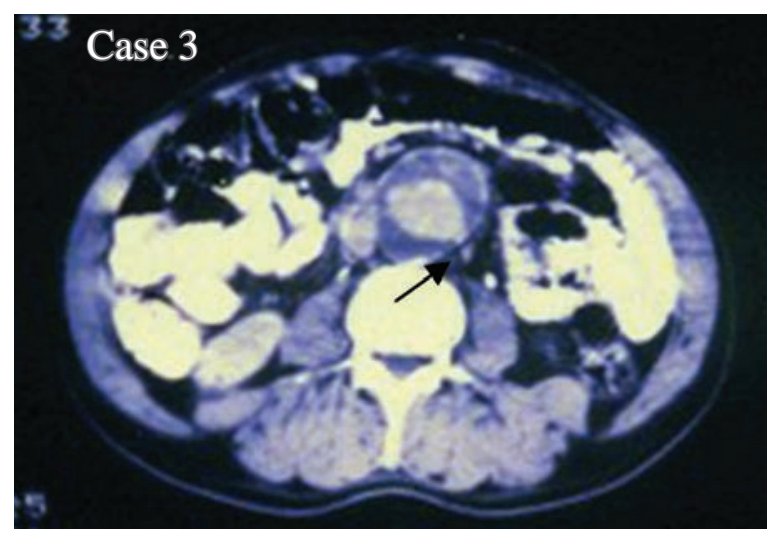

Figure (15): CTA of leaking AAA, $12 \mathrm{~cm}$ in diameter.

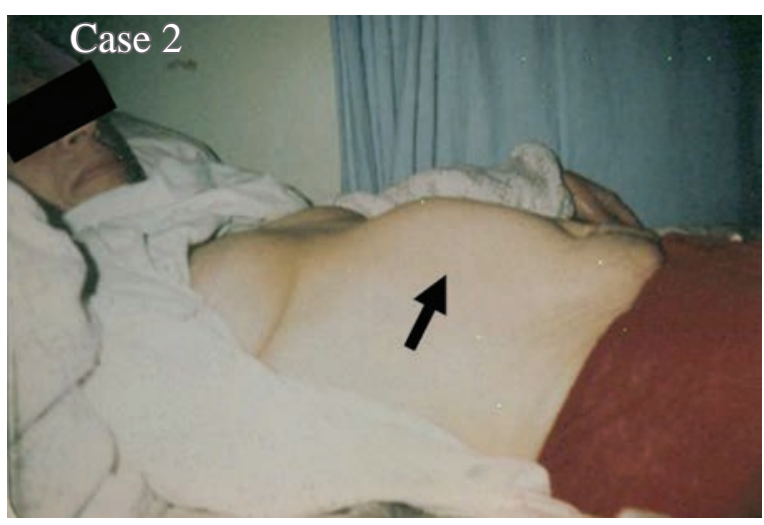

Figure (12): Photo of the abdomen before operation (aneurysm bulge).

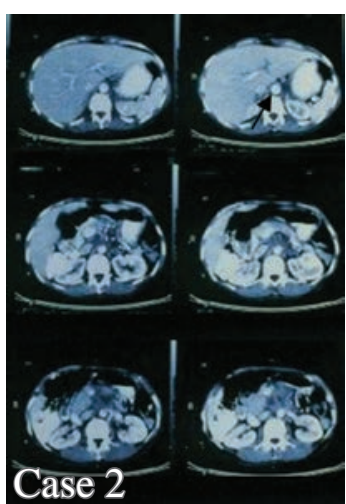

Figure (14): Postoperative CTA after 30 days showed that the abdominal aorta was intact.

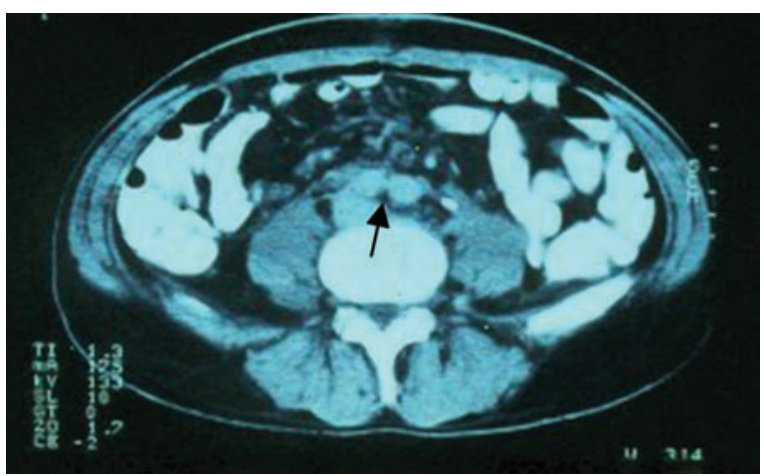

Figure (16): Postoperative CTA after 30 days of operation of $A A A$, showing the two limbs of the graft.

Table (1): The clinical presentation of AAAs.

\begin{tabular}{|l|l|l|}
\hline \multicolumn{1}{|c|}{ Symptoms \& Signs } & No. of cases & \multicolumn{1}{c|}{$\%$} \\
\hline$\cdot$ abdominal pain & 26 & 92.85 \\
\hline$\cdot$ Back pain & 22 & 78.57 \\
\hline$\cdot$ Pulsatile Abdominal mass & 28 & 100.00 \\
\hline$\cdot$ Acute abdomen (Leaking AAA) & 2 & 7.14 \\
\hline$\cdot$ Associated hypertension & 25 & 89.28 \\
\hline
\end{tabular}


Table (2): The preoperative risk factors in 28 patients with huge AAAs.

\begin{tabular}{|l|l|c|}
\hline \multicolumn{1}{|c|}{ Risk factors } & Number & \multicolumn{1}{c|}{$\mathbf{c}$} \\
\hline$\cdot$ hypertension & 25 & 89.28 \\
\hline$\cdot$ Smoking & 20 & 71.42 \\
\hline$\cdot$ Hypercholestrolaemia & 16 & 57.14 \\
\hline$\cdot$ Diabetes Mellitus & 10 & 35.71 \\
\hline$\cdot$ Obesity & 8 & 28.57 \\
\hline - Myocardial infarction & 7 & 25.00 \\
\hline - Renal insufficiency & 2 & 7.14 \\
\hline
\end{tabular}

Table (3): The site \& types of AAAs.

\begin{tabular}{|l|l|l|l|}
\hline Site & Type & No. of cases & $\%$ \\
\hline$\cdot$ Infrarenal A & Atherosclerotic (Fusiform) & 23 & 82.14 \\
\hline$\cdot$ Infrarenal + common iliac A. aneurysms & Atherosclerotic (Fusiform) & 3 & 10.71 \\
\hline$\cdot$ Juxtarenal A. & Mycotic (Saccular) & 1 & 3.57 \\
\hline$\cdot$ Suprarenal A. & Mycotic (Saccular) & 1 & 3.57 \\
\hline
\end{tabular}

Table (4): The morbidity of AAAs within 30 postoperative days.

\begin{tabular}{|l|l|l|}
\hline \multicolumn{1}{|c|}{ Morbidity } & No. of cases & \multicolumn{1}{c|}{$\%$} \\
\hline$\cdot$ Myocardial infarction & 4 & 14.28 \\
\hline$\cdot$ Renal failure* & 2 & 7.14 \\
\hline$\cdot$ Femoral A. thrombosis & 2 & 7.14 \\
\hline$\cdot$ Distal embolization & 2 & 7.14 \\
\hline$\cdot$ Spontaneous pneumothorax & 1 & 3.57 \\
\hline
\end{tabular}

* The two cases with renal failure had preoperative renal insufficiency with serum creatinine level of 1.6 and $1.9 \mathrm{mg} / \mathrm{dl}$.

Table (5): The mortality of AAAs within 30 postoperative days.

\begin{tabular}{|l|l|l|}
\hline Cause of death & No. of cases & $\mathbf{\%}$ \\
\hline$\cdot$ Myocardial infarction & 2 & 7.14 \\
\hline$\cdot$ Renal failure & 1 & 3.57 \\
\hline$\cdot$ Leaking AAA* & 1 & 3.57 \\
\hline$\cdot$ Total mortality & 4 & 14.28 \\
\hline
\end{tabular}

* The case which was presented with leaking AAA confirmed by CTA and urgent operation was done.

The early benefit of EVAR was completely lost in long-term, with higher aneurysmrelated mortality than in the open repair. It was found that no significant difference in total mortality between the two techniques. Secondary rupture was reported only after EVAR (endograft rupture). This explained long-term increase in aneurysm-related mortality. ${ }^{9}$

In this study, we consider that AAA $10 \mathrm{~cm}$ in diameter or more is huge abdominal aortic aneurysm. All the huge AAA are treated by open repair, because all the contraindications of EVAR are present in huge size, in addition, to the presence of huge pulsating abdominal mass. If we put endovascular graft the mass 
still present. Also, endograft migration is common, endograft rupture or death. ${ }^{15}$

The total mortality rate in our study was four cases (14.28\%), two of myocardial infarction, one with renal failure (3.57\%) and one with leaking AAA (3.57\%). Because most of the morbidity \& mortality of AAAs repair are caused by cardiac, renal and pulmonary dysfunction, so preoperative care of these organs is important to improve the survival rate. 6

For these reasons, open aneurysm repair is mandatory in the treatment of huge abdominal aortic aneurysms, (HAAAs).

\section{Conclusions:}

We consider any AAA ten $\mathrm{cm}$ or more in diameter as a huge aneurysm.

Huge Abdominal Aortic Aneurysm is one of contraindications of EVAR.

Open repair of the huge abdominal aortic aneurysm is mandatory and can be performed safely, despite of associated medical risks.

Preoperative care of cardiac, renal and pulmonary systems decreases the morbidity and mortality of open repair of huge abdominal aortic aneurysm and improves the survival rate.

\section{Reference:}

1- Thomas DM, Hulten EA, Ellis ST, Anderson DM, Anderson N, McRae F: Open versus endovascular repair of abdominal aortic aneurysm in the elective and emergent setting in a pooled population of 37,781 patients: A systematic review and meta-analysis. ISRN Cardiol 2014; 2014: 1-9.

2- Silverberg E, Boring CC, Squires TS: Cancer statistics, 1990. Cancer 1990; 40: 9-26.

3- Johnston KW, Rutherford RB, Tilson MD, Shah DM, Hollier L, Stanley JC: Suggested standards for reporting on arterial aneurysms. Subcommittee on Reporting Standards for Arterial Aneurysms, Ad Hoc Committee on Reporting Standards, society for Vascular Surgery and North American Chapter, International Society for Cardiovascular surgery. J Vasc Surg 1991; 13: 452-458.

4- Lindholt JS, Juul S, Fasting H, Henneberg EW: Screening for abdominal aortic aneurysms: Single centre randomized controlled trial. BMJ 2005; 330: 750.
5- Lederle FA, Walker JM, Reinke DB: Selective screening for abdominal aortic aneurysms with physical examination and ultrasound. Arch Intern Med 1988; 148: 1753-1756.

6- Bown MJ, Sutton AJ, Bell PR, Sayers RD: A meta-analysis of 50 years of ruptured abdominal aortic aneurysm repair. Br J Surg 2002; 89(6): 714-730.

7- Brown LC, Powell JT: Risk factors for aneurysm rupture in patients kept under ultrasound surveillance. UK Small Aneurysm Trial Participants. Ann Surg 1999; 230: 289-296.

8- Campbell JJ, Bell DD, Gaspar MR: Selective use of arteriography in the assessment of aortic aneurysm repair. Ann Vasc Surg 1990; 4: 419-423.

9- Greenhalgh RM, Powell JT: Endovascular repair of abdominal aortic aneurysm. $N$ Engl J Med 2008; 358(5): 494-501.

10- Ballard DJ, Filardo G, Fowkes G, Powell JT: Surgery for small asymptomatic abdominal aortic aneurysms. Cochrane Database Syst Rev 2008; 4: CD001835.

11- Hallett JW Jr, Marshall DM, Petterson TM, Gray DT, Bower TC, Cherry KJ Jr, et al. Graft-related complications after abdominal aortic aneurysm repair: Reassurance from a 36-year population-based experience. J Vasc Surg 1997; 25: 277-284.

12- Conrad MF, Crawford RS, Pedraza JD, Brewster DC, Lamuraglia GM, Corey M, et al: Long-term durability of open abdominal aortic aneurysm repair. $J$ Vasc Surg 2007; 46: 669-675.

13- Gupta PK, Ramanan B, Lynch TG, Gupta H, Fang X, Balters M, et al: Endovascular repair of abdominal aortic aneurysm does not improve early survival versus open repair in patients younger than 60 years. Eur J Vasc Endovasc Surg 2012; 43: 506-512.

14- Parodi JC, Palmaz JC, Barone HD: Transfemoral intraluminal graft implantation for abdominal aortic aneurysms. Ann Vasc Surg 1991; 5: 491-499.

15- Harris P, Vallabhaneni S, Desgranges P, Becquemin JP, van Marrewijk C, et al: Incidence and risk factors of late rupture, conversion, and death after endovascular repair of infrarenal aortic aneurysms: The EUROSTAR experience. $J$ Vasc Surg 2000; 32: 739-749.

16- Schermerhorn ML, Finlayson SR, Fillinger MF, Buth J, van Marrewijk C, Cronenwett JL: Life expectancy after endovascular versus open abdominal aortic aneurysm 
repair: results of a decision analysis model on the basis of data from EUROSTAR. $J$ Vasc Surg 2002; 36: 1112-1120.

17- Raval MV, Eskandari MK: Outcomes of elective abdominal aortic aneurysm repair among the elderly: Endovascular versus open repair. Surgery 2012; 151: 245-260.

18- Rutherford RB: Randomized EVAR trials and advent of level I evidence: A paradigm shift in management of large abdominal aortic aneurysms. Semin Vasc Surg 2006; 19: 69-74.

19- Lederle FA, Kane RL, MacDonald R, Wilt TJ: Systemic review: Repair of unruptured abdominal aortic aneurysm. Ann Intern Med 2007; 146: 735-741.

20- EVAR Trial Participants: Endovascular aneurysm repair versus open repair in patients with abdominal aortic aneurysm (EVAR trial 1): Randomized controlled trial. Lancet 2005; 365: 2179-2186.

21- Blankensteijn JD, de Jong SE, Prinssen M, van der Ham AC, Buth J, van Sterkenburg SM, et al: Two-year outcomes after conventional or endovascular repair of abdominal aortic aneurysms. $N$ Engl $\mathrm{J}$ Med 2005; 352: 2398-2405.

22- Stather PW, Sidloff D, Dattani N, Choke E, Bown MJ, Sayers RD: Systematic review and meta-analysis of the early and late outcomes of open and endovascular repair of abdominal aortic aneurysm. Br J Surg 2013; 100: 863-872.

23- Greenhalgh RM, Brown LC, Kwong GP, Powell JT, Thompson SG: Comparison of endovascular aneurysm repair with open repair in patients with abdominal aortic aneurysm (EVAR trial 1), 30-day operative mortality results: Randomized controlled trial. Lancet 2004; 364: 843-848.

24- Hallin A, Bergqvist D, Holmberg L: Literature review of surgical management of abdominal aortic aneurysm. Eur J Vasc Endovasc Surg 2001; 22: 197-204. 